\title{
Cellulosic Nanomaterial Production Via Fermentation by Komagataeibacter sp. SFCB22-18 Isolated from Ripened Persimmons
}

\author{
Myung Soo Park ${ }^{1 \dagger}$, Young Hoon Jung ${ }^{2 \dagger}$, Seung-Yoon $\mathrm{Oh}^{1}$, Min Ji Kim ${ }^{1}$, Won Yeong Bang ${ }^{2}$, and Young Woon Lim ${ }^{1 *}$ \\ ${ }^{1}$ School of Biological Sciences and Institution of Microbiology, Seoul National University, Seoul 08826, Republic of Korea \\ ${ }^{2}$ School of Food Science and Biotechnology, Food and Bio-industry Institute, Kyungpook National University, Daegu 41566, Republic of Korea
}

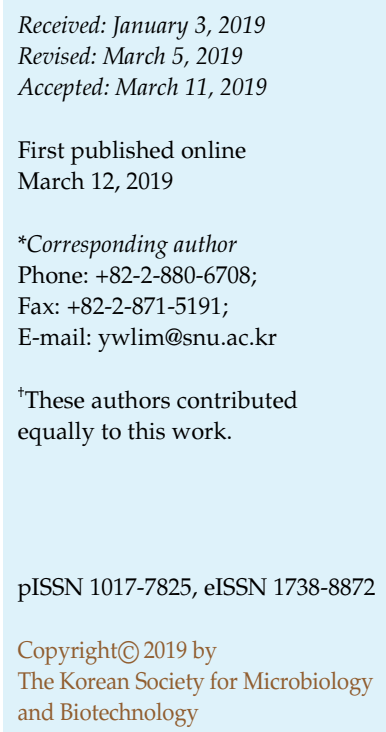

\begin{abstract}
Bacterial nanocellulose (BNC) which is generally synthesized by several species of bacteria has a wide variety of industrial uses, particularly in the food and material industries. However, the low levels of BNC production during the fermentation process should be overcome to reduce its production cost. Therefore, in this study, we screened and identified a new cellulose-producing bacterium, optimized production of the cellulose, and investigated the morphological properties of the cellulosic materials. Out of 147 bacterial isolates from ripened fruits and traditional vinegars, strain SFCB22-18 showed the highest capacity for BNC production and was identified as Komagataeibacter sp. based on 16S rRNA sequence analysis. During 6-week fermentation of the strain using an optimized medium containing 3.0\% glucose, $2.5 \%$ yeast extract, $0.24 \%$ acetic acid, $0.27 \% \mathrm{Na}_{2} \mathrm{HPO}_{4}$, and $0.5 \%$ ethanol at $30^{\circ} \mathrm{C}$, about $5 \mathrm{~g} / 1$ of cellulosic material was produced. Both imaging and IR analysis proved that the produced cellulose would be nanoscale bacterial cellulose.
\end{abstract}

Keywords: Cellulosic nanomaterial, bacterial nanocellulose, Komagataeibacter, ripened persimmon, fermentation

\section{Introduction}

Cellulose is one of the most abundant polymers in the world [1] and is composed of $\beta$-1,4-linked glucose units. It is generally synthesized by plants; however, bacteria are also capable of producing cellulose that is structurally similar to plant cellulose through fermentation [2]. This cellulose type is known as bacterial nanocellulose (BNC), which can be categorized as a cellulosic nanomaterial. It is produced by a number of bacterial species, including Acetobacter, Alcaligenes, Azotobacter, Rhizobium, Pseudomonas, Salmonella, and Sarcina [3], which can be often observed during vinegar fermentation or fruit spoilage. However, the cultivation of cellulose-producing bacteria is inefficient since these bacteria require high oxygen levels and a long adaptation period, thereby resulting in high cost when produced on a commercial scale [4]. Hence, significant cost reduction by improvement of fermentation efficiency is required to make cellulose production a commercially viable option.
Until now, cellulose-producing bacteria have been isolated from various sources, such as fruits, flowers, fermented foods, and vegetable wastes [5-7]. However, the strategies like isolation and identification of new strains producing BNC as well as optimization of the fermentation process are still promising to obtain a high yield of BNC. Therefore, researchers have continued to investigate the isolation of microorganisms capable of greater BNC production. This goal is particularly vital since this nanomaterial has many possible applications arising from its diverse traits. For example, its gelation ability has made BNC a source of traditional foods like "Nata de coco" [8]. BNC is also expected to be an additive for use as a thickener, texturizer, and/or dietary fiber in food such as "Kombucha tea" [9, 10]. Besides the food industry, this cellulose nanomaterial can be used as a valuable material in the medical field in reconstructive surgery, in cell and tissue engineering as a drug carrier, and as electronic paper due to its high purity, high water content, high bio-compatibility, high mechanical strength, and gas permeability [6, 11-14]. In the present 
study, the isolation and identification of celluloseproducing bacteria were performed from various sources including ripened fruits and traditional vinegars. Then, the fermentation conditions were optimized and the properties of the cellulose pellicles were identified.

\section{Materials and Methods}

\section{Isolation and Screening of Cellulose-Producing Bacteria}

To isolate bacteria that produce cellulose pellicles, we collected ripened fruits (citrus, persimmon, and tomato) and traditional vinegars made from apricot, banana, grape, lespedeza, peach, persimmon, Sanghwang mushroom, and rice. A piece of tissue from each fruit was dissected and placed in a $50-\mathrm{ml}$ conical tube with $5 \mathrm{ml}$ of distilled water. The tubes were vortexed and $100 \mu \mathrm{l}$ of the resultant liquid was spread on Hestrin-Schramm medium (HS medium; $\mathrm{pH} 6.0$ ) containing $2.0 \%$ glucose, $0.5 \%$ yeast extract, $0.5 \%$ peptone, $0.27 \% \mathrm{Na}_{2} \mathrm{HPO}_{4}, 0.115 \%$ citric acid, and $2.0 \%$ agar [15]. Traditional vinegars $(100 \mu \mathrm{l})$ were diluted $1 / 5$ and $1 / 10$ and spread on HS plates. After incubation at $30^{\circ} \mathrm{C}$ for 5 days, individual isolates were transferred to new HS agar plates and further incubated at $30^{\circ} \mathrm{C}$. The strains were also stored in $20 \%(\mathrm{w} / \mathrm{w})$ glycerol at $-80^{\circ} \mathrm{C}$ in the Seoul National University Fungal Collection (SFC, Korea) for further use.

\section{Selection and Identification of BNC-Producing Strains}

To investigate BNC-producing ability, all strains isolated from ripened fruits and traditional vinegars were individually inoculated in $20 \mathrm{ml}$ HS media. The formation of pellicles on the surface of the culture media was visually verified and the BNCproducing ability was compared after cultivation at $30^{\circ} \mathrm{C}$ for 7 days [16]. Then, the strain that produced the highest amount of cellulose was selected for further experiments.

The selected bacterial strain was identified based on $16 \mathrm{~S}$ rRNA sequence analysis. Bacterial $16 \mathrm{~S}$ rDNA was amplified using a Maxime PCR PreMix Kit (iNtRON Biotechnology, Korea) with 27F forward and 1492R reverse primers [17]. Colony PCR amplification was performed with a PCR mixture containing $1.0 \mu \mathrm{l}$ of each primer, $23.0 \mu \mathrm{l}$ sterilized distilled water, and one colony of a bacterial strain. PCR conditions were as follows: denaturation at $95^{\circ} \mathrm{C}$ for $10 \mathrm{~min}, 35$ cycles of elongation at $95^{\circ} \mathrm{C}$ for $40 \mathrm{sec}$, at $55^{\circ} \mathrm{C}$ for $40 \mathrm{sec}$, and at $72^{\circ} \mathrm{C}$ for $60 \mathrm{sec}$, and final extension at $72^{\circ} \mathrm{C}$ for $5 \mathrm{~min}$. PCR products were separated and visualized via $1 \%$ agarose gel electrophoresis, and purified using an Expin PCR Purification Kit (GeneAll, Korea). Sequencing was performed using an automated DNA analyzer system (PRISM 3730XL DNA Analyzer, Applied Biosystems, USA) from Macrogen (Korea). The sequences were checked and edited using MEGA v.5 [18]. Identification was conducted using both BLAST, against the EzBioCloud database [19], and phylogenetic analysis based on the neighbor-joining method with Kimura-2 parameter and 1,000 bootstrap replicates. The sequence was deposited into GenBank under accession number MH045739.

\section{Optimization of Culture Conditions}

Growth of the selected strain was examined by inoculating the strain in HS medium in $250-\mathrm{ml}$ flasks and incubating at $30^{\circ} \mathrm{C}$ for 7 days with shaking at $200 \mathrm{rpm}$. Culture viability was examined by plating daily on HS agar after vigorous shaking and filtering through sterile four-layered gauze to detach cells from the cellulose, and counting the number of colony forming units (CFU) of viable bacterial cells. For BNC production, a colony of the selected strain was inoculated in $100 \mathrm{ml}$ HS medium in a $250-\mathrm{ml}$ flask and incubated at $30^{\circ} \mathrm{C}$ for 3 days with shaking at $200 \mathrm{rpm}$. Five percent $(\mathrm{v} / \mathrm{v})$ of the culture broth supernatant was then inoculated in $100 \mathrm{ml}$ of medium in 250-ml flasks for the optimization of culture conditions.

To optimize culture conditions, the effect of various temperatures $\left(20^{\circ} \mathrm{C}, 25^{\circ} \mathrm{C}, 30^{\circ} \mathrm{C}\right.$, and $\left.37^{\circ} \mathrm{C}\right)$ and agitation on $\mathrm{BNC}$ production for 7 days was compared. BNC amounts were also compared to that of Komagataeibacter xylinus (ATCC10245), which is a well-known cellulose-producing bacteria [20]. In addition, the composition of the growth medium was optimized by adding various carbon sources (glucose, mannitol, fructose, sucrose, maltose, and lactose; concentrations $1 \%-5 \%$ ), nitrogen sources (yeast extract, corn steep liquor, beef extract, malt extract, and peptone; $0.5 \%-3 \%$ ), acids (acetic acid, lactic acid, and succinic acid; $0 \%-0.3 \%$ ), phosphate sources $\left(\mathrm{KH}_{2} \mathrm{PO}_{4}, \mathrm{~K}_{2} \mathrm{HPO}_{4}, \mathrm{NaH}_{2} \mathrm{PO}_{4}\right.$, and $\left.\left(\mathrm{NH}_{4}\right)_{2} \mathrm{HPO}_{4} ; 0.27 \%\right)$ and ethanol $0 \%-2.5 \%$.

To determine statistical significance, a one-way analysis of variance with post hoc testing and a least significant difference test were performed using Statistica software (version 7.1, StatSoft, Tulsa, OK).

\section{Bacterial Nanocellulose Purification}

BNC pellicles produced at the air-liquid interface of the medium were immersed in $0.3 \mathrm{~N} \mathrm{NaOH}$ at $90^{\circ} \mathrm{C}$ for $20 \mathrm{~min}$, placed on filter paper (No. 2; Advantec, Japan), and rinsed with distilled water until the $\mathrm{pH}$ of filtrate became neutral to ensure the complete removal of sodium hydroxide. The total solids content of the filtered pellicles was obtained by drying at $80^{\circ} \mathrm{C}$ for $48 \mathrm{~h}$ in triplicate.

\section{Analysis of BNC Properties by Scanning Electron Microscopy} (SEM) and Fourier Transform Infrared Spectroscopy (FTIR)

To evaluate the conformational characteristics of the BNC fibrils obtained from the medium, the BNC pellicles were analyzed by FTIR (Nicolet iS5 FTIR Spectrometer, Thermo Scientific, USA) and SEM (SU8220; Hitachi, Japan). For FTIR analysis, the lyophilized sample was cut into pieces of a predetermined size and spectra in the range of 500 to $4,000 \mathrm{~cm}^{-1}$ were obtained at a resolution of $4 \mathrm{~cm}^{-1}$, with 16 scans for each sample in the transmission mode. For SEM imaging, the lyophilized sample was coated with a thin platinum film and all images were taken at an accelerating voltage of $15 \mathrm{kV}$. 


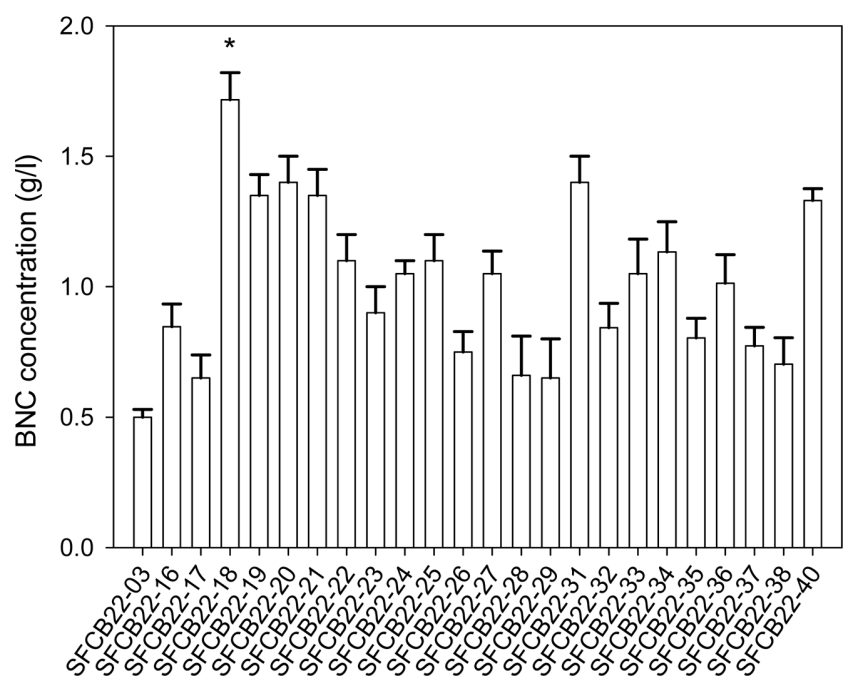

Fig. 1. Comparison of bacterial nanocellulose production by strains isolated from ripened persimmons.

Box with asterisk indicates significantly different at $p<0.05$.

\section{Results and Discussion}

\section{Screening of Nanocellulose-Producing Bacteria and} Identification of the Isolate

A total of 147 bacterial strains were isolated from various fruits (citrus fruits-11 strains, persimmons-92, and tomatoes9) and traditional vinegars (apricot-4, banana-1, Chinese matrimony vine-2, lespedeza-10, peach-3, persimmon-6,
Sanghwang mushroom-2, and rice-7) using HS medium. Among them, 24 strains isolated from ripened persimmons only produced extracellular compounds, which could be cellulose polymer. Particularly, SFCB22-18 produced the greatest amount of polymer (1.70 g/1) (Fig. 1).

Strain SFCB22-18 was identified based on its 16S rRNA sequence. Primary identification using BLAST against the EzBioCloud database showed similarities of 99.7\%, 99.6\%, and $99.6 \%$ to K. intermedius TF2 ${ }^{\mathrm{T}}, \mathrm{K}$. oboediens DSM $11826^{\mathrm{T}}$, and K. medellinensis NBRC $3288^{\mathrm{T}}$, respectively. Phylogenetic analysis based on the neighbor-joining method showed that strain SFCB22-18 was close to K. medellinensis NBRC $3288^{\mathrm{T}}$ with a high support value $(80 \%)$, while it was clustered with several Komagataeibacter spp. (Fig. 2). Thus, the isolated strain remained as Komagataeibacter sp. SFCB2218 because of its unclear phylogenetic relationship with closely related species.

So far, either acetic acid-producing species or polysaccharide-producing species have been isolated from persimmons and persimmon vinegars. For example, Acetobacter syzygii, K. intermedius (= Gluconacetobacter intermedius) and K. europaeus were observed during the acetification of persimmon [21]. In addition, Gluconacetobacter sp. RKY5, K. xylinus TJU-S8, K. xylinus KJ-1 (= A. xylinum), and $K$. intermedius TF2 were observed in persimmon vinegars $[22,23]$. Mostly, they are producing insoluble cellulose polymers and soluble extracellular polysaccharides. In this study, we have found that some of the bacterial stains

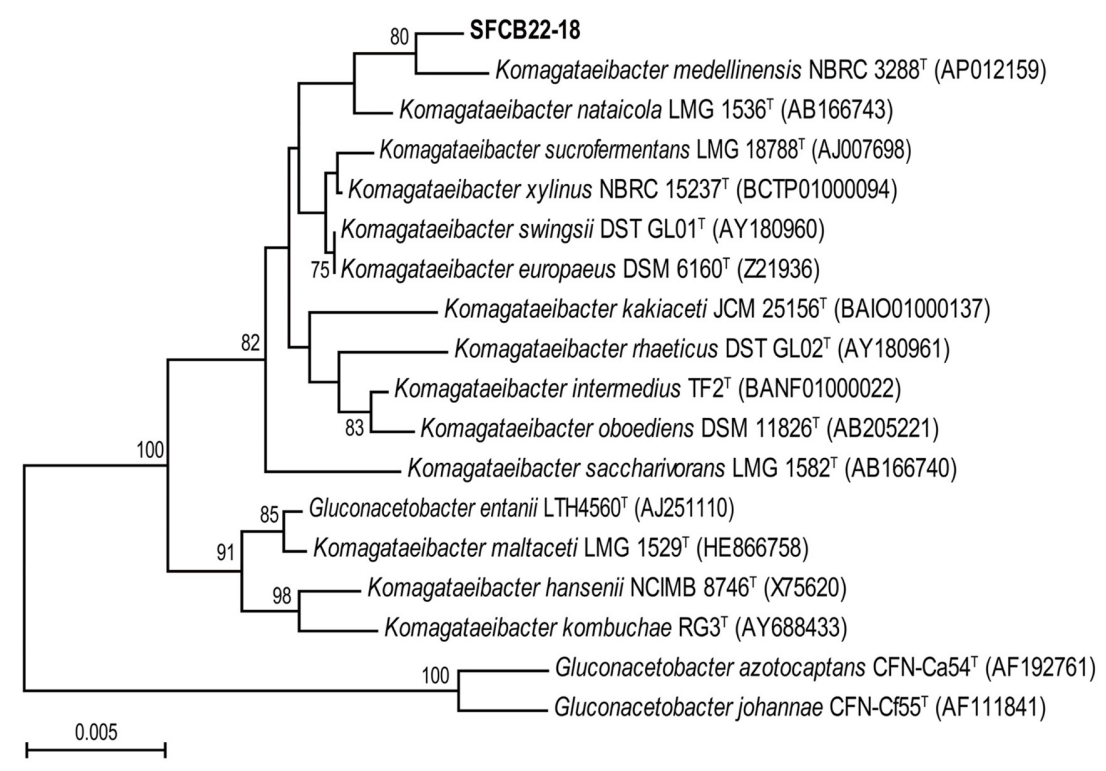

Fig. 2. Neighbor-joining tree inferred from $16 \mathrm{~S}$ rRNA showing the relationship of strain SFCB22-18 with the most closely related members of the genus Komagataeibacter.

Bootstrap scores of $>70$ are presented at the nodes. The scale bar indicates the number of nucleotide substitutions per site. 


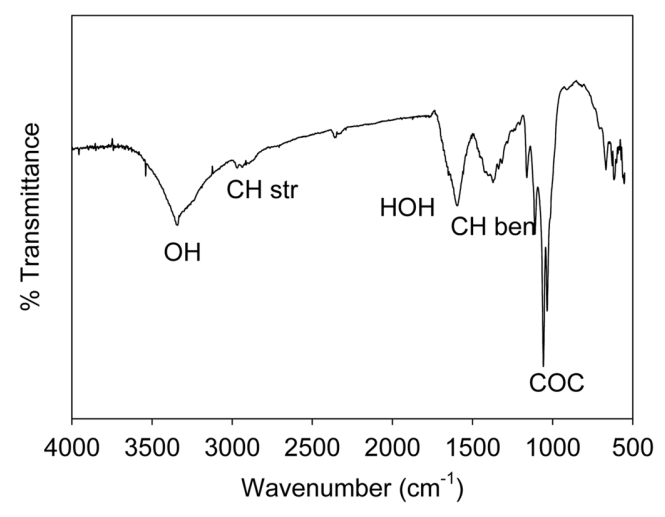

Fig. 3. FTIR spectra of bacterial nanocellulose.

$\mathrm{OH}$ : O-H stretching, $\mathrm{CH}$ str: $\mathrm{C}-\mathrm{H}$ stretching, $\mathrm{HOH}$ : H-O-H stretching, $\mathrm{CH}$ ben: symetric deformation and bending vibration of $\mathrm{C}-\mathrm{H}, \mathrm{COC}$ : C-O-C stretching

isolated from ripened persimmons were able to produce insoluble extracellular polysaccharide. The extracellular polysaccharide which would be assumed as cellulose was examined with FTIR (Fig. 3). A typical absorption spectrum of BNC was observed, such as $\mathrm{OH}$ stretching at $3,400 \mathrm{~cm}^{-1}$, $\mathrm{CH}$ stretching at 2,897 $\mathrm{cm}^{-1}$, COC stretching at $1,030 \mathrm{~cm}^{-1}$, etc. $[24,25]$. Thus, we assumed that the produced extracellular pellicles from Komagataeibacter sp. SFCB22-18 are mainly composed of cellulose.

\section{Optimization of Culture Parameters}

$\mathrm{BNC}$ is a major form of exopolysaccharide that is produced on the surface of bacterial cultures in a slow fermentation process. In addition, BNC production is dependent on the strain type and on favorable cultivation conditions [26]. Thus, in this study, the growth and cellulose production in Komagataeibacter sp. SFCB22-18 under various fermentation conditions were investigated. The growth curve of Komagataeibacter sp. SFCB22-18 cultivated on HS media at $30{ }^{\circ} \mathrm{C}$ showed a steep increase to $3.8 \times 10^{6} \mathrm{CFU} / \mathrm{ml}$ in 3 days. Since there was no further significant increase in cell growth during the 7 days of cultivation, the inoculums cultured for 3 days were used to optimize the batch fermentation conditions, including medium components, on BNC production.

Initially, the effects of fermentation temperature and agitation on BNC production were investigated (Fig. 4). As the culture temperature increased from $20^{\circ} \mathrm{C}$ to $30^{\circ} \mathrm{C}, \mathrm{BNC}$ concentration after 7 days, fermentation increased from $1.2 \mathrm{~g} / 1$ to $1.6 \mathrm{~g} / 1$ (Fig. 4A). However, a further increase in temperature to $37^{\circ} \mathrm{C}$ reduced $\mathrm{BNC}$ production, which is similar to previous results for BNC production in K. xylinus
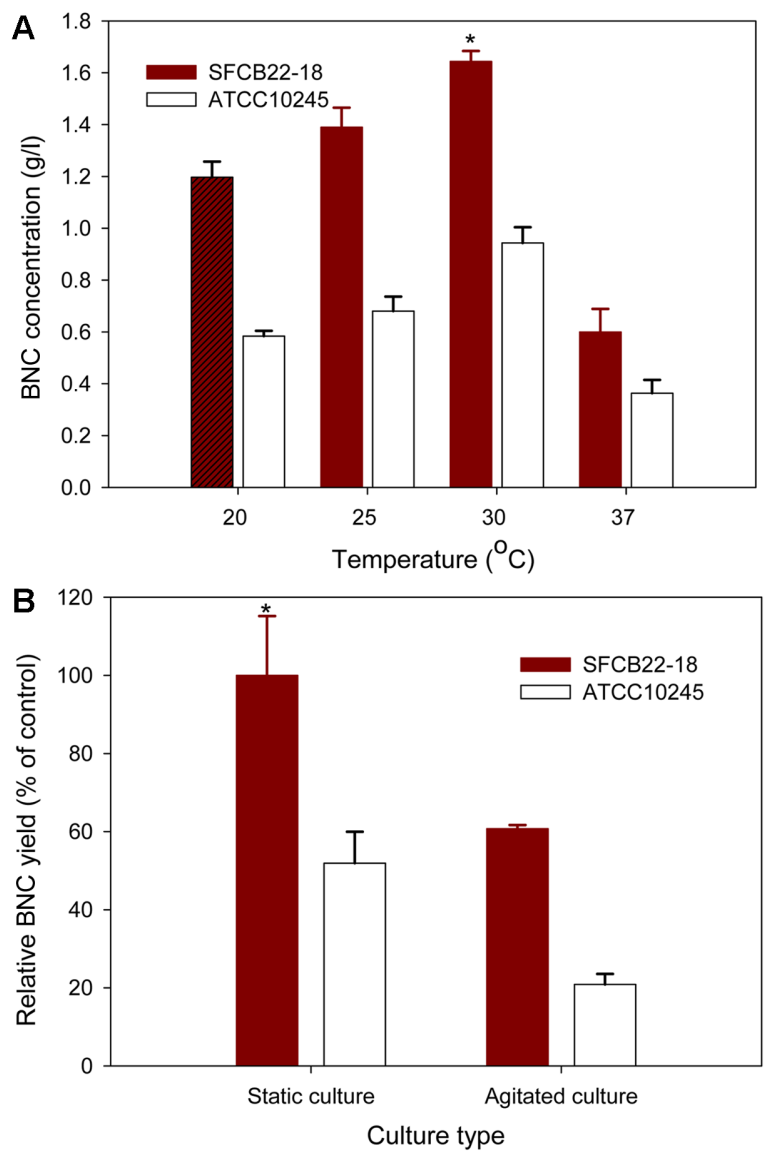

Fig. 4. Effects of (A) cultivation temperature and (B) agitation on the concentration of bacterial nanocellulose produced by Komagataeibacter sp. SFCB22-18.

Box with asterisk indicates significantly different at $p<0.05$.

0416 and Komagataeibacter sp. PAP1 [27, 28]. The fermentation temperature of $30^{\circ} \mathrm{C}$ was found to be optimal for efficient cellulose production in Komagataeibacter sp. SFCB22-18. Meanwhile, agitation during cultivation also affected the quantity and quality of the synthesized cellulose. When Komagataeibacter sp. SFCB22-18 was cultured with vigorous shaking at $200 \mathrm{rpm}$, BNC production significantly decreased by approximately $40 \%$ (Fig. 4B). These results suggested that agitation is not necessary to obtain a high amount of cellulose, probably due to a limitation in binding between newly synthesized BNC and existing BNC since cells might not have had enough time to anchor BNC at such high agitations [29]. Furthermore, a higher amount of cellulose was produced by Komagataeibacter sp. SFCB22-18 than the reference strain K. xylinus (ATCC10245). As a result, static culture condition was chosen for further experiments.

Next, the effects of different sources of carbon and nitrogen and their concentrations on BNC production were 

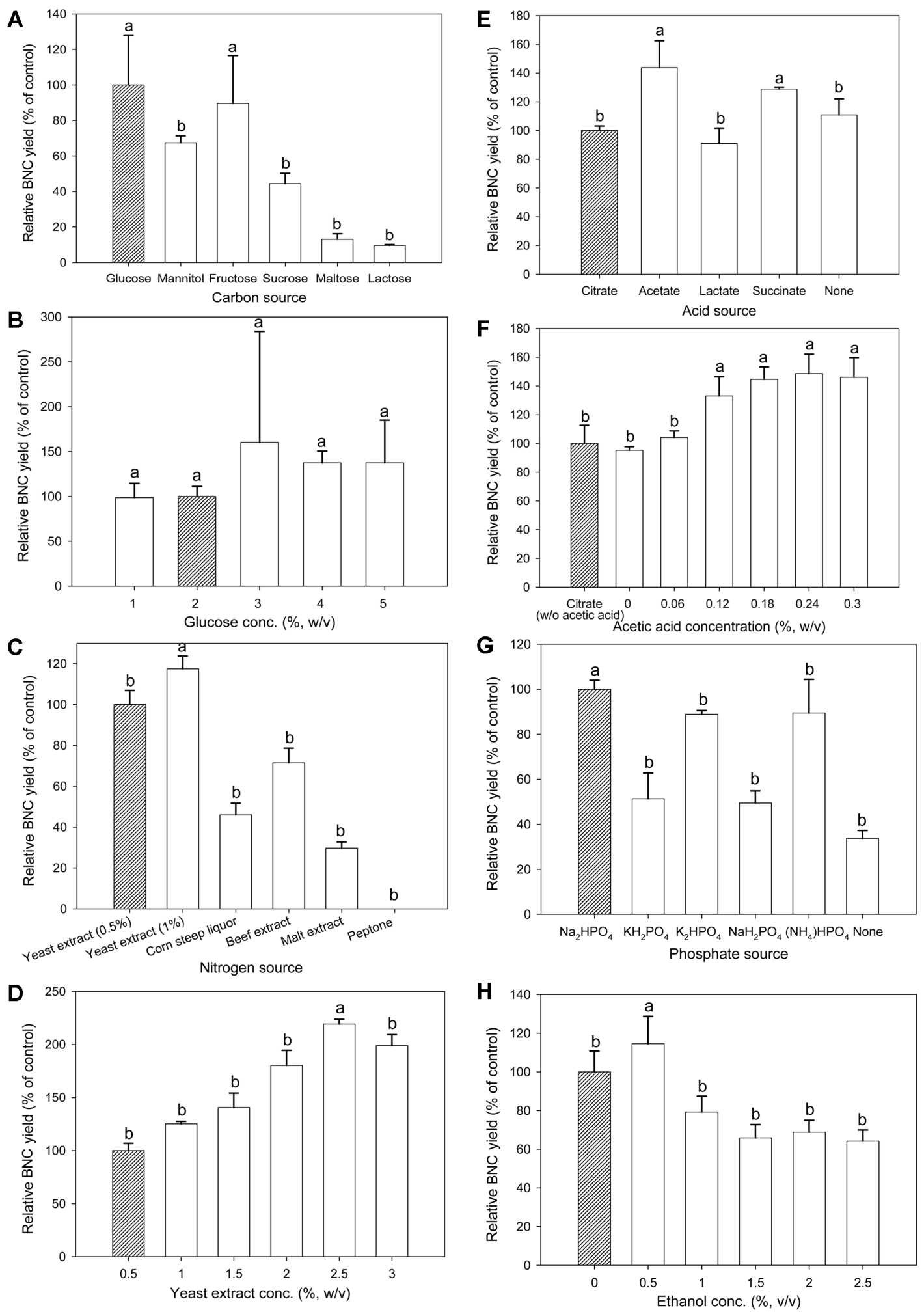

Fig. 5. Effects of (A) carbon source, (B) glucose concentration, (C) nitrogen source, (D) yeast extract concentration, (E) acid source, $(\mathbf{F})$ acid concentration, $(\mathbf{G})$ phosphate source, and $(\mathbf{H})$ ethanol concentration on the concentration of bacterial nanocellulose (BNC) produced by Komagataeibacter sp. SFCB22-18.

Box with patterns refers to the condition of Hestrin-Schramm (HS) medium. Bars with different letters are significantly different at $p<0.05$. 
investigated (Figs. 5A-5D). Among the various types of carbon sources used (glucose, fructose, lactose, maltose, mannitol, and sucrose), glucose addition $(2 \% \mathrm{w} / \mathrm{v}$, standard glucose concentration in HS media) led to the highest production of $\mathrm{BNC}$, followed by the addition of the same concentrations of fructose and mannitol (Fig. 5A). According to previous studies, the optimal carbon source depends on the bacterial strain since bacteria have diverse metabolic activities. For example, K. medellinensis preferred glucose over sucrose and fructose, however, the amount of cellulose produced by G. xylinus was higher in the presence of fructose or glycerol than in the presence of glucose [30, 31]. When the glucose concentration increased to $3 \%(\mathrm{w} / \mathrm{v})$, BNC production improved by $160 \%$ (Fig. 5B). When glucose is readily available, bacteria do not need to convert accessible carbohydrate sources into glucose molecules before polymerization into $\mathrm{BNC}$, a process that uses energy. Thus, it is likely that glucose addition to the culture medium may lead to a greater production of cellulose. However, a further increase in glucose concentration to $5 \%$ did not show any significant increase in BNC production. Thus, a glucose concentration of $3 \%(\mathrm{w} / \mathrm{v})$ was selected as the optimal carbon source for efficient BNC production by Komagataeibacter sp. SFCB22-18.

Among the various nitrogen sources used (yeast extract, corn steep liquor, beef extract, malt extract, and peptone), yeast extract ( $1 \%$ addition) led to the highest BNC production (approximate increase of $120 \%$ over BNC production in HS media) (Fig. 5C), which is in good agreement with results from previous studies for BNC production in Acetobacter sp. V6 and A. lovaniensis HBB5 $[32,33]$. As the yeast extract concentration in the culture media increased to $2.5 \%$, the amount of BNC produced increased to around $220 \%$ of that of the $0.5 \%$ yeast extract found in typical HS medium (Fig. 5D). Since further additions of yeast extract $(3.0 \%)$ did not show beneficial effects in BNC production, $2.5 \%$ was chosen as the optimal yeast extract concentration for efficient cellulose production by Komagataeibacter sp. SFCB22-18.

Third, the effects of different sources of acid and the concentrations on BNC production were investigated (Figs. 5E and 5F). Various acid sources such as citrate, acetate, lactate, and succinate at concentrations of $0.115 \%$ were used individually to maintain the $\mathrm{pH}$ of the modified HS medium. Among them, the acetate-containing medium showed the highest BNC production, which was approximately $140 \%$ of that in standard HS medium (Fig. 5E). It is probably attributable to the higher $\mathrm{pKa}$ value of acetate than the other acid sources; thereby indicating that acetate is the least toxic to cells during fermentation at $\mathrm{pH}$ 6.0. As the acetate concentration increased from $0-0.24 \%$, the concentration of BNC pellicles continued to increase up to $149 \%$ of that produced in standard HS medium containing $0.115 \%$ citrate (Fig. 5F). Thus, $0.24 \%$ acetate concentration was selected as optimal for efficient BNC production by Komagataeibacter sp. SFCB22-18.

Fourth, the effects of the different sources of phosphate and the concentrations on $\mathrm{BNC}$ production were investigated (Fig. 5G). HS medium containing $\mathrm{Na}_{2} \mathrm{HPO}_{4}$ led to the greatest production of BNC. HS media supplemented with $\mathrm{K}_{2} \mathrm{HPO}_{4}$ and $\left(\mathrm{NH}_{4}\right)_{2} \mathrm{HPO}_{4}$ also showed comparable BNC concentration. However, $\mathrm{KH}_{2} \mathrm{PO}_{4}$ and $\mathrm{NaH}_{2} \mathrm{PO}_{4}$ inhibited BNC production. This may be due to the fact that $\mathrm{Na}_{2} \mathrm{HPO}_{4}$ is more basic than $\mathrm{NaH}_{2} \mathrm{PO}_{4}$, which can result in greater buffering activity during fermentation.

Finally, the effect of ethanol concentration was also investigated (Fig. $5 \mathrm{H}$ ) because some acetic acid bacteria are capable of oxidizing ethanol [34], which might be used as an energy source. When $0.5 \%$ ethanol was added, BNC concentration in the medium after 7 days of cultivation increased 1.15 fold over production in HS medium without ethanol. However, further ethanol additions did not enhance BNC production probably because of the toxicity of ethanol and thus, $0.5 \%$ ethanol concentration was considered as optimal for efficient BNC production by Komagataeibacter sp. SFCB22-18.

\section{Time Profile of Bacterial Nanocellulose Production under Optimized Conditions}

BNC production by the newly isolated Komagataeibacter sp. SFCB22-18 was explored under the optimized

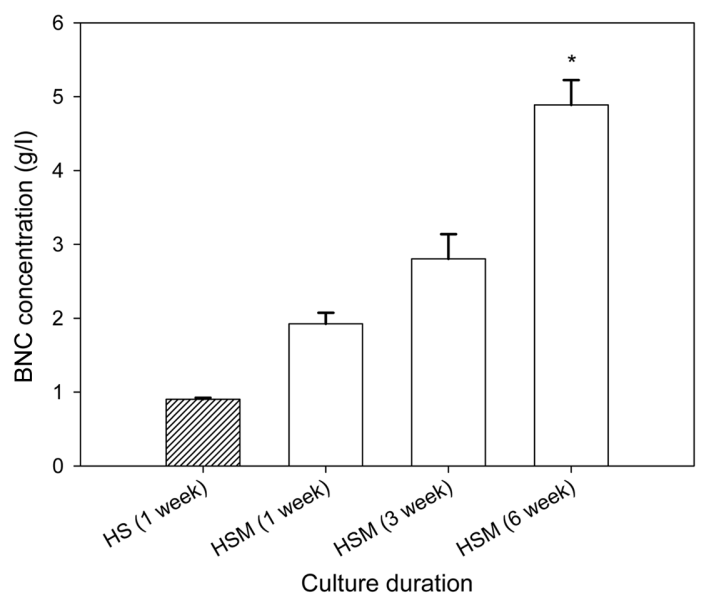

Fig. 6. Bacterial nanocellulose concentration grown under optimized conditions during the six weeks of fermentation. Bars with asterisk indicates significantly different at $p<0.05$. 

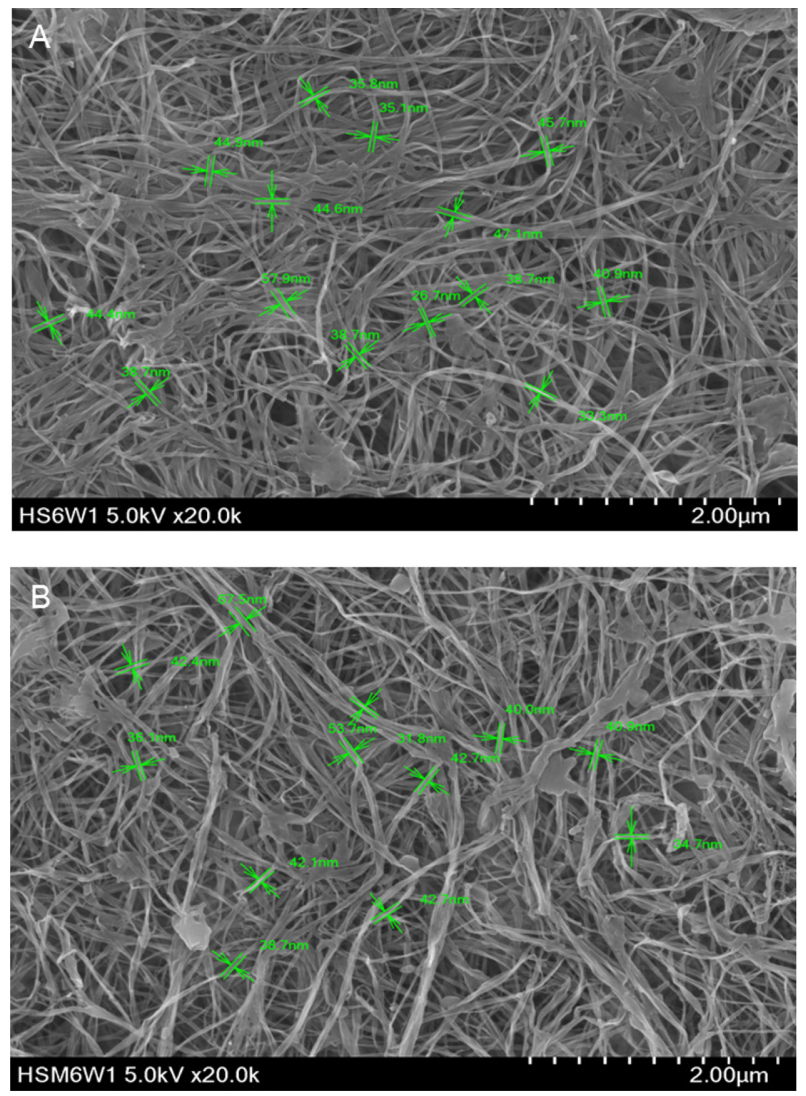

Fig. 7. SEM images of bacterial nanocellulose synthesized by Komagataeibacter sp. SFCB22-18 after 6 weeks of cultivation in (A) typical Hestrin-Schramm (HS) medium and (B) modified medium (HSM).

conditions of $3.0 \%$ glucose, $2.5 \%$ yeast extract, $0.24 \%$ acetic acid, and $0.5 \%$ ethanol with $0.27 \% \mathrm{Na}_{2} \mathrm{HPO}_{4}$ as a phosphate source at $30^{\circ} \mathrm{C}$ without shaking. In comparison with BNC production in HS medium, Komagataeibacter sp. SFCB22-18 grown on the optimized medium produced about 2-fold higher BNC amounts (Fig. 6). In addition, BNC produced by Komagataeibacter sp. SFCB22-18 in the optimized medium increased continuously to up to $5 \mathrm{~g} / 1$ during the six-week cultivation period, which is comparable to other studies showing $2-5 \mathrm{~g} / 1$ by Gluconacetobacter sp. RKY5 and $K$. sucrofermentans DSM 15973 [22, 35, 36]. SEM images also showed that BC was composed of thread-like cellulosic nanofibrils whose diameter was about $20-70 \mathrm{~nm}$ regardless of cultured medium according to random measurement of the fibrils (Fig. 7). Therefore, the strain, Komagataeibacter sp. SFCB22-18, has high potential for the production of bacterial nanocellulose.

In conclusion, we isolated an extracellular compoundproducing strain, Komagataeibacter sp. SFCB22-18, from ripened persimmons. The produced pellicles were characterized and identified with SEM and FTIR as nanocellulose. During the cultivation, approximately a 2fold increase in BNC production was investigated using the optimized medium of $3.0 \%$ glucose, $2.5 \%$ yeast extract, $0.24 \%$ acetic acid, and $0.5 \%$ ethanol with $0.27 \% \mathrm{Na}_{2} \mathrm{HPO}_{4}$ at $30^{\circ} \mathrm{C}$ without shaking and 7 days of cultivation. The highest BNC concentration $(4.9 \mathrm{~g} / 1)$ was obtained after 6 weeks of cultivation. Therefore, the newly isolated strain, Komagataeibacter sp. SFCB22-18, was identified as a good producer of BNC which can be used in the food and material industries.

\section{Acknowledgments}

This work (Grant No. C0004405) was supported by the Business for Cooperative R\&D among Industry, Academy, and Research Institute of the Korean Small and Medium Business Administration in 2012. This research was also supported by the Basic Science Research Program through the National Research Foundation of Korea (NRF), the Ministry of Education (Grant No. 03030504).

\section{Conflict of Interest}

The authors have no financial conflicts of interest to declare.

\section{References}

1. Moniri M, Boroumandmoghaddam A, Azizi S, Abdul RR, Bin AA, Zuhainis SW, et al. 2017. Production and status of bacterial cellulose in biomedical engineering. Nanomater. 7: 257-283.

2. Jonas R, Farah LF. 1998. Production and application of microbial cellulose. Polym. Degrad. Stab. 59: 101-106.

3. Raghunathan D. 2013. Production of microbial cellulose from the new bacterial strain isolated from temple wash waters. Int. J. Curr. Microbiol. Appl. Sci. 2: 275-290.

4. Esa F, Tasirin SM, Rahman NA. 2014. Overview of bacterial cellulose production and application. Agric. Agric. Sci. Procedia 2: 113-119.

5. Ruka DR, Simon GP, Dean KM. 2012. Altering the growth conditions of Gluconacetobacter xylinus to maximize the yield of bacterial cellulose. Carbohydr. Polym. 89: 13-622.

6. Rangaswamy BE, Vanitha KP, Hungund BS. 2015. Microbial cellulose production from bacteria isolated from rotten fruit. Int. J. Polym. Sci. 2015: 1-8.

7. Sharafi SM, Rasooli I, Beheshti-Maal K. 2010. Isolation, characterization and optimization of indigenous acetic acid bacteria and evaluation of their preservation methods. Iran J. Microbiol. 2: 38-45. 
8. Yamada Y, Hosono R, Lisdyanti P, Widyastuti Y, Saono S, Uchimura $\mathrm{T}$, et al. 1999. Identification of acetic acid bacteria isolated from Indonesian sources, especially of isolates classified in the genus Gluconobacter. J. Gen. Appl. Microbiol. 45: 23-28.

9. Nguyen VT, Flanagan B, Gidley MJ, Dykes GA. 2008. Characterization of cellulose production by a Gluconacetobacter xylinus strain from Kombucha. Curr. Microbiol. 57: 449-453.

10. Okiyama A, Motoki M, Yamanaka S. 1992. Bacterial cellulose II. Processing of the gelatinous cellulose for food materials. Food Hydrocoll. 6: 479-487.

11. Prashant RC, Ishwar BB, Shrikant AS, Rekha SS. 2009. Microbial cellulose: fermentative production and applications. Food Technol. Biotechnol. 47: 107-124.

12. Kamoun EA, Kenawy E-RS, Chen X. 2017. A review on polymeric hydrogel membranes for wound dressing applications: PVA-based hydrogel dressings. J. Adv. Res. 8: 217-233.

13. Sukara E, Meliawati R. 2014. Potential values of bacterial cellulose for industrial applications. J. Selulosa 4: 7-16.

14. Ullah H, Santos HA, Khan T. 2016. Applications of bacterial cellulose in food, cosmetics and drug delivery. Cellulose 23: 2291-2314.

15. Sannino A, Demitri C, Madaghiele M. 2009. Biodegradable cellulose-based hydrogels: design and applications. Mater. 2: 353-373.

16. Schramm M, Hestrin S. 1954. Factors affecting production of cellulose at the air/liquid interface of a culture of Acetobacter xylinum. J. Gen. Microbiol. 11: 123-129.

17. Ahn YH., Park JH, Go SH, Jun HK. 2007. Characterization of bacterial cellulose production by Gluconacetobacter sp. JH232. J. Life Sci. 17: 1582-1586.

18. Weisburg WG, Barns SM, Pelletier DA, Lane DJ. 1991. $16 S$ ribosomal DNA amplification for phylogenetic study. J. Bacteriol. 173: 697-703.

19. Tamura K, Peterson D, Peterson N, Stecher G, Nei M, Kumar S. 2011. MEGA5: molecular evolutionary genetics analysis using maximum likelihood, evolutionary distance, and maximum parsimony methods. Mol. Biol. Evol. 28: 2731-2739.

20. Yoon SH, Ha SM, Kwon S, Lim J, Kim Y, Seo H, et al. 2017. Introducing EzBioCloud: a taxonomically united database of $16 \mathrm{~S}$ rRNA gene sequences and whole-genome assemblies. Int. J. Syst. Evol. Microbiol. 67: 1613-1617.

21. El-Saied H, El-Diwany AI, Basta AH, Atwa NA, El-Ghwas DE. 2008. Production and characterization of economical bacterial cellulose. BioResources. 3: 1196-1217

22. Hidalgo C, Mateo E, Mas A, Torija MJ. 2012. Identification of yeast and acetic acid bacteria isolated from the fermentation and acetification of persimmon (Diospyros kaki). Food Microbiol. 30: 98-104.

23. Kim SY, Kim JN, Wee YJ, Park DH, Ryu HW. 2006. Production of bacterial cellulose by Gluconacetobacter sp. RKY5 isolated from persimmon vinegar, pp. 705-715. In McMillan, JD, Adney, WS, Mielenz, JR, Klasson, KT (eds.),
Twenty-Seventh symposium on biotechnology for fuels and chemicals, Humana Press, Totowa, NJ.

24. Auta R, Adamus G, Kwiecien M, Radecka I, Hooley P. 2017. Production and characterization of bacterial cellulose before and after enzymatic hydrolysis. Afr. J. Biotechnol. 16: 470-482.

25. Khattak WA, Khan T, Ul-Islam M, Ullah MW, Khan S, Wahid F, et al. 2015. Production, characterization and biological features of bacterial cellulose from scum obtained druing preparation of sugarcane jiggery (gur). J. Food Sci. Technol. 52: 8343-8349.

26. Du R, Zhao F, Peng Q, Zhou Z, Han Y. 2018. Production and characterization of bacterial cellulose produced by Gluconacetobacter xylinus isolated from Chinese persimmon vinegar. Carbohydr. Polymers. 194: 200-207.

27. Lustri WR, Barud HGdO, Barud HdS, Peres MFS, Gutierrez J, Tercjak A, et al. 2015. Microbial cellulose - biosynthesis mechanisms and medical applications, pp.133-157. In Poletto M, Junior HLO (eds.), Cellulose - fundamental aspects and current trends, InTech, Rijeka.

28. Zahan KA, Nordin K, Mustapha M, Zairi MNM. 2015. Effect of incubation temperature on growth of Acetobacter xylinum 0416 and bacterial cellulose production. Appl. Mech. Mater. 815: 3-8.

29. Suwanposri A, Yukphan P, Yamada Y, Ochaikul D. 2014. Statistical optimisation of culture conditions for biocellulose production by Komagataeibacter sp. PAP1 using soya bean whey. Maejo Int. J. Sci. Technol. 8: 1-14.

30. Czaja W, Romanovicz D, Brown RM. 2004. Structural investigations of microbial cellulose produced in stationary and agitated culture. Cellulose 11: 403-411.

31. Molina-Ramírez C, Castro M, Osorio M, Torres-Taborda M, Gómez B, Zuluaga R, et al. 2017. Effect of different carbon sources on bacterial nanocellulose production and structure using the low $\mathrm{pH}$ resistant strain Komagataeibacter medellinensis. Mater. 10: 639-651.

32. Römling U, Galperin MY. 2015. Bacterial cellulose biosynthesis: diversity of operons, subunits, products and functions. Trends Microbiol. 23: 545-557.

33. Esin PÇ, Halil B. 2011. Effect of various carbon and nitrogen sources on cellulose synthesis by Acetobacter lovaniensis HBB5. Afr. J. Biotechnol. 10: 5346-5354.

34. Son HJ, Kim HG, Kim KK, Kim HS, Kim YG, Lee SJ. 2013. Increased production of bacterial cellulose by Acetobacter sp. V6 in synthetic media under shaking culture conditions. Bioresour. Technol. 86: 215-219.

35. Park JK, Jung JY, Park YH. 2003. Cellulose production by Gluconacetobacter hansenii in a medium containing ethanol. Biotechnol. Lett. 25: 2055-2059.

36. Tsouko E, Kourmentza C, Ladakis D, Kopsahelis N, Mandala I, Papanikolaou S, et al. 2015. Bacterial cellulose production from industrial waste and by-product streams. Int. J. Mol. Sci. 16: 14832-14849. 